\title{
Impact of Platinum Loading on Performance and Degradation of Polymer Electrolyte Fuel Cell Electrodes Studied in a Rainbow Stack
}

which has been published in final form at FUEL CELLS [http://onlinelibrary.wiley.com/doi/10.1002/fuce.201700099/full].

\author{
Pawel Gazdzicki $^{{ }^{*}}$, Jens Mitzel ${ }^{1}$, Andreas M. Dreizler ${ }^{1}$, Mathias Schulze ${ }^{1}$, K. Andreas \\ Friedrich $^{1,2}$
}

${ }^{1}$ German Aerospace Center (DLR), Institute of Engineering Thermodynamics, Pfaffenwaldring 38-40, 70569 Stuttgart, Germany

${ }^{2}$ University of Stuttgart, Institute for Energy Storage, Pfaffenwaldring 31, 70569 Stuttgart, Germany

[*]Corresponding author: pawel.gazdzicki@dlr.de

\begin{abstract}
The paper focuses on the investigation of durability and performance of a low temperature polymer electrolyte membrane fuel cell (PEMFC) stack as a function of Pt loading in automotive test conditions. Major motivations are problems related to the need to reduce the amount of Pt in membrane electrode assemblies (MEAs) in order to make PEMFC more competitive. The particular challenge is to maintain sufficiently high performance and longterm durability. The study shows that for cathode Pt loadings below $0.2 \mathrm{mg} \mathrm{cm}^{-2}$ and for current densities exceeding $1 \mathrm{~A} \mathrm{~cm}^{-2}$ a sudden drop of performance is observed. The same threshold value is found for the increase of irreversible voltage losses which lead to an intense reduction of PEMFC durability for cathodic loadings below $0.2 \mathrm{mg} \mathrm{cm}^{-2}$. Another durability issue at cathodic Pt loadings $<0.4 \mathrm{mg} \mathrm{cm}^{-2}$ is the acceleration of reversible degradation,
\end{abstract}


which leads to a strong voltage drop during continues fuel cell operation (i.e. without a recovery interruption).

Keywords: Fuel cells, rainbow stack, durability, Pt loading, irreversible degradation, reversible degradation.

\section{Introduction}

Platinum which is a key material for fuel cells has been listed as critical raw material (CRM) and is in the focus of the European Commission's strategy to reduce the dependence on platinum group metals (PGMs) [1]. The readiness and functionality of totally PGM-free PEMFCs, however, has not progressed far enough to enter the market. Low-PGM loaded fuel cells, on the other hand, have demonstrated gradual progress. To make fuel cell electrical vehicles (FCEV) competitive regarding total cost and sustainable regarding PGM usage and to reduce the amount of CRM in the fuel cell sector, the PGM content in automotive PEMFC stacks should not exceed the PGM content required for catalytic exhaust converters of typical internal combustion engine (ICE) cars which is around $6 \mathrm{~g}$ PGM taking into account the distribution of gasoline and diesel ICEs in Europe in 2016 [2-3]. Based on $90 \mathrm{~kW}$ average power of a new vehicle in 2016 [4], the targeted PGM loading of a PEMFC stack for FCEV with a maximum power density of $1 \mathrm{~W} \mathrm{~cm}$ should be below $0.1 \mathrm{mg} \mathrm{cm}^{-2}$ to avoid an increase of the amount of Pt in circulation due high volume production of FCEV. Such a drastic reduction of Pt loading which implies severe performance and durability issues is still a big challenge for the entire fuel cell community. In fact, the Pt loading of Pt/C based MEAs could be decreased down to $0.2 \mathrm{mg} \mathrm{cm}^{-2}$ maintaining $1 \mathrm{~W} \mathrm{~cm}^{-2}$ performance in the European IMPACT project [5]. The durability, however, remains still an issue.

One of the main obstacles to achieve high performance at low Pt loadings is the local oxygen transport resistance of the cathode [6]. Several groups found that, in contrast to the reduction 
of the cathodic loading, a reduction of anodic loading to $0.05 \mathrm{mg} \mathrm{cm}^{-2}$ or even below does not influence cell performance significantly $[7,8]$. The reason is that the hydrogen oxidation reaction is several orders of magnitude faster than the oxygen reduction reaction and therefore less catalytically active material is necessary at the anode [9]. In order to improve PEMFC performance numerous approaches have been followed in the past. Qi et al. [10] varied the wt\% of $\mathrm{Pt} / \mathrm{C}$ and found that $20 \% \mathrm{Pt} / \mathrm{C}$ and $30 \%$ Nafion is best combination in case of the $\mathrm{E}$ TEK catalyst material. Other groups optimized performance of low loaded MEAs by using ionomer-free NSTF (nanostructured thin films) to reduce the oxygen transport resistance $[11,12]$. Others have studied catalyst layer preparation techniques [8] or have used stable carbon composite catalysts for catalyst layer preparation [13]. Kriston et al. [14] have found and confirmed by modelling that although the mass transport resistance increases upon lowering of the Pt loadings, the mass activity of the catalyst increases, too. To reduce the oxygen transport resistance it was proposed to develop new highly permeable ionomers to be used in the cathode catalyst layers [6]. According to Ahn et al. [15], on the other hand, higher ionomer concentrations in the catalyst layer are beneficial to maintain performance at low loadings.

One of most important issues regarding the durability of PEMFC with carbon supported Pt catalysts is catalyst layer degradation due to Pt particle growth, dissolution, ionomer degradation and carbon corrosion [16-18]. All these effects are detrimental for fuel cell longterm performance leading to severe voltage losses caused by the reduction of the electrochemically active surface area (ECSA) especially at low Pt loadings [11]. Moreover, it was shown that MEA durability depends on the initial Pt particle size, whereby medium size particles of around $7 \mathrm{~nm}$ show a good balance between performance and durability [19]. A degradation study of MEAs with Pt loadings of 0.15 and $0.40 \mathrm{mg} \mathrm{cm}^{-2}$ has shown that mass transport over-potentials at low cathode loadings increase faster with potential cycling than that of high loadings [20]. 
Generally, a huge amount of different studies regarding the influence of the Pt loadings on the performance or degradation has been conducted. The degradation studies have been usually performed using either accelerated stress tests (AST) or in constant operation conditions. Automotive operation conditions, however, exhibit a highly dynamic load profile with shutdown interruptions that have a significant impact on the recovery of reversible losses [21-23]. To the best of our knowledge, a systematic study on the impact of Pt-loading on both performance and degradation performed in automotive operation conditions has not been published so far. In this paper a corresponding study has been performed by using a rainbow stack with differently Pt loaded MEAs to determine threshold loadings and other limiting factors that are related lowering of Pt loading in Pt/C based PEMFCs.

\section{Experimental}

\subsection{Stack and test hardware}

The DLR-developed 19 cells stack which is used in this study is a research test stack containing graphite composite bipolar plates with an active area of $140 \mathrm{~cm}^{2}$. The stack is operated with hydrogen and air supplied in a counter-flow configuration. A thermostat with deionized water was used to adjust the stack temperature. The stack was operated in an inhouse developed $5 \mathrm{~kW}$ fuel cell stack test station that allows parallel monitoring of single cell voltages. The gas humidification was adjusted by using direct water evaporators. All stack operating parameters are controlled according to the control strategies for reliable and comparable stack benchmarking defined by the European project Stack-Test [24]. Detailed information about the stack and the test station can be found elsewhere [25].

The stack was used as a rainbow stack, i.e. it was equipped with MEAs with different Pt loadings at the anode and the cathode. The used MEAs along with their position in the stack (Cell No. with No. 1 at media inlets) and the Pt loadings are summarized in Table 1. The first 
3, the last 3 as well as the center cell No. 10 are commercial reference MEAs from Johnson Matthey Fuel Cells. Cells 4-9 and 11-16 are two nominally identical sequences of R\&D test catalyst coated membranes (CCMs) with various Pt loadings purchased from EWii Fuel Cells, referred to as MEA1, MEA2,..., MEA6. The two sequences are used to address the possible impact of the cell position in the stack on the performance and degradation evaluation since degradation heterogeneities occur in stack tests meaning that the performance and especially the degradation of individual cells may strongly depend on its position within the stack [25, 26]. These degradation heterogeneities develop with time. In a previous study performed using the same stack hardware completely equipped with MEAs from Johnson Matthey Fuel Cells, the inhomogeneities become significant after continuous operation of several hundreds of hours [25]. In the present study, however, the operation periods of only $142 \mathrm{~h}$ limit the extent of variances due to the reversible degradation in individual cells. Hence, the effect of cell position on degradation is expected to be minor.

Furthermore, the first and the last three cells are used to exclude influences from the gas inlets and outlets as well as the metal endplates of the stack. The CCMs had an active area of 118 mm x 118 mm. The EWii Fuel Cells research CCMs are manufactured based on DLR requirements by using $50 \mathrm{wt} \% \mathrm{Pt} / \mathrm{C}$ and Nafion ${ }^{\circledR} \mathrm{XL}$ membrane. Hence, the different loadings were adjusted by just varying the thickness of the catalyst layers. In addition, 25BC gas diffusion layers (GDLs) from SGL Carbon have been used on both anode and cathode side.

\subsection{Operation and test conditions}

The performance and durability tests have been performed at $80^{\circ} \mathrm{C}$ stack temperature, $50 \%$ RH and 1.5 bar absolute pressure at anode and cathode. Performance curves have been measured at $\mathrm{H}_{2}$ and air stoichiometric ratios of 1.5 and 2.0, respectively, with minimum gas flows corresponding to a current density of $0.2 \mathrm{~A} \mathrm{~cm}^{-2}$. The durability test has been carried out at constant flow conditions corresponding to a $\mathrm{H}_{2}$ stoichiometry of 1.5 and an air 
stoichiometry of 2.0 at a current density of $1 \mathrm{~A} \mathrm{~cm}^{-2} .5 .0$ grade hydrogen and nitrogen as well as filtered and pressurized ambient air were used for all experiments.

Cyclic voltammetry (CV) was applied on the anode and on the cathode of each cell in the range of $0.07-1.2 \mathrm{~V}$ with $20 \mathrm{mV} \mathrm{s}^{-1}$ sweep rate. Both counter and working electrode compartments, were fed with $2.7 \mathrm{l} \mathrm{min}^{-1} \mathrm{H}_{2}$ and $5.3 \mathrm{l} \mathrm{min}^{-1} \mathrm{~N}_{2}$, respectively, at $100 \% \mathrm{RH}$ and 1 bar absolute pressure. The stack temperature was held at $80^{\circ} \mathrm{C}$.

\subsection{Durability testing}

The durability test consists of three test blocks that are divided into different test phases according to the test protocol provided in Table 2. Start-up and preconditioning was performed according to the Stack-Test Master Document - TM 2.00 [27]. For performance curve measurements and FC-DLC (fuel cell dynamic load cycle) durability testing the StackTest Modules P08 and D02 have been used [27]. Between the test blocks, a defined soak time procedure was applied to the stack to recover occurring reversible losses: After switching off the load, the stack was purged with $\mathrm{N}_{2}$ and cooled down to room temperature, then anode and cathode outlets were opened to allow air entering the anode and cathode compartments.

Before restarting the stack after the soak time, it was first purged with humid $\mathrm{N}_{2}$ while heating up to $80^{\circ} \mathrm{C}$. Subsequently, fuel cell operation and conditioning was started by using hydrogen and air. For more details on the used recovery procedure of reversible degradation losses, the reader is referred to our recent publication [23].

\section{Results and Discussion}

\subsection{Evaluation of BoT performances versus Pt loading}

At begin of test (BoT), the stack was characterized by recording CVs and measuring the performance characteristics of each cell, whereby the latter are provided in Figure 1 (A). The BoT ECSA (electrochemical active surface area) of the anodes and cathodes are shown in 
Figure 1 (B). The ECSAs were calculated from the $\mathrm{H}_{2}$ desorption signals in the range $70-400$ $\mathrm{mV}$ using $0.21 \mathrm{mC} \mathrm{cm}^{-2}$ [28] as the charge to oxidize one monolayer of hydrogen adsorbed on Pt. It is noted that the further evaluation of performance is based on EWii MEAs only to avoid the complexity due to differences in composition and structure of EWii and Johnson Matthey electrodes.

The ECSA dependence on the nominal loading is plotted in Figure 2. The data show a linear increase of ECSA with increasing Pt loadings for both anode $\left(\mathrm{R}^{2}=0.98\right)$ and cathode $\left(\mathrm{R}^{2}=\right.$ 0.99). An exception is cell 15, i.e. MEA5, which exhibits a strong deviation that is obviously caused by a substantially lower loading than specified. Therefore, the cell has not been considered in the further data analysis, except the ECSA evaluation.

The impact of Pt loading on cell performance was studied based on the data from Figure 1 (A). To discriminate between the Pt loading influence at each electrode on the cell performance, cells with constant cathode loading of $0.4 \mathrm{mg} \mathrm{cm}^{-2}$ and cells with a constant anode loading of $0.05 \mathrm{mg} \mathrm{cm}^{-2}$ have been evaluated separately as shown in Figure 3 (A) and (B).

It was found that the cell voltages do not change upon variation of the anodic loading in the range $0.05-0.20 \mathrm{mg} \mathrm{cm}^{-2}$ which is consistent with a previous paper by Gasteiger et al. [7] who observed that a reduction of the anodic Pt loading down to $0.05 \mathrm{mg} \mathrm{cm}^{-2}$ has no influence on the performance.

The cell voltage changes as a function of the cathodic loadings, as shown in Figure 3 (B) for different current densities, are substantial, especially at high current densities. For each current density the data was fitted by two linear functions covering the Pt loading in the range 0.05-0.30 $\mathrm{mg} \mathrm{cm}^{-2}$ (dashed lines) and $0.20-0.40 \mathrm{mg} \mathrm{cm}^{-2}$ (dotted lines). The slopes of these linear functions versus the current density are plotted in Figure 3 (C). Clearly, for high Pt loadings $0.20-0.40 \mathrm{mg} \mathrm{cm}^{-2}$ (open symbols) an almost linear increase of the slopes by factor 2 is observed with increasing current densities up to $1.4 \mathrm{~A} \mathrm{~cm}^{-2}$. For low Pt loadings in the 
range of $0.05-0.30 \mathrm{mg} \mathrm{cm}^{-2}$, a slight increase is observed if the current density is increased from 0 to $1 \mathrm{~A} \mathrm{~cm}^{-2}$, comparable to the slopes for the Pt loadings $0.20-0.40 \mathrm{mg} \mathrm{cm}^{-2}$. At current densities higher than $1.0 \mathrm{~A} \mathrm{~cm}^{-2}$ a dramatic increase can be detected. Specifically, the slope of the dashed curve in panel (A) at $1.4 \mathrm{~A} \mathrm{~cm}^{-2}$ is 7 times higher than at $0 \mathrm{~A} \mathrm{~cm}^{-2}$ and 3 times higher than at $1 \mathrm{~A} \mathrm{~cm}^{-2}$. Hence, two threshold values can be identified for the behavior of low loaded MEAs. $1 \mathrm{~A} \mathrm{~cm}^{-2}$ represents the threshold for the current density. Below this threshold the performance decreases slightly and linearly when the cathodic Pt loading is reduced. At current densities higher than $1.0 \mathrm{~A} \mathrm{~cm}^{-2}$, the impact of the cathodic Pt loading increases significantly. Additionally, a cathodic Pt loading of around $0.2 \mathrm{mg} \mathrm{cm}^{-2}$ represents the upper threshold value where the cell performance drops significantly when the cell is operated at current densities above $1 \mathrm{~A} \mathrm{~cm}^{-2}$. For E-TEK electrodes, a similar Pt loading threshold was found in the range of $0.10-0.15 \mathrm{mg} \mathrm{cm}^{-2}$ [10]. The existence of the threshold values implies that the cathodic Pt loading cannot be lowered continuously by reducing the thickness of the catalyst layer while using the same materials. Below a certain value, the performance drop at high current densities is very substantial and requires material improvements to maintain high performances. Likely reasons for the significantly lower performance of low loaded cathodes at high current densities are associated with high oxygen mass conversion rates at the platinum catalyst surface together with water management issues in the thin catalyst layers. The high water production rate at high current densities can cause partial flooding of the catalyst layer resulting in an increased mass transport resistance for the oxygen since the catalyst layer pores are blocked. Therefore, the observed low performance and increased degradation at low loadings may not only be explained by Pt loading but are also due to electrode thickness; drying effects at 50\% RH and high gas flows may be much more pronounced for thin electrodes compared to thick ones. Additionally, local oxygen transport resistances, caused by dense ionomer layers near to the catalyst surface, were identified to have a significant impact on the performance of low loaded cathodes because 
higher local oxygen mass transport rates due to the limited platinum surface sites are required [19].

\subsection{Degradation versus Pt loading}

The degradation test has been performed by using the FC-DLC dynamic test protocol for automotive conditions [21, 22]. A single test cycle is presented in Figure 4 (A). The protocol comprises current densities from $0 \mathrm{~A} \mathrm{~cm}^{-2}(\mathrm{OCV})$ to $1 \mathrm{~A} \mathrm{~cm}^{-2}$. For clarity of presentation only voltage values recorded at three selected current density values $\left(0.05,0.42\right.$, and $1.00 \mathrm{~A} \mathrm{~cm}^{-2}$ as labelled in the figure) are evaluated in the following. In Figure 4 (B), the corresponding three stack voltage levels are plotted for the entire test duration, including the three test blocks, during which the voltage levels are influenced by reversible and irreversible degradation effects, and the recovery interruptions, which lead to recovery of the reversible voltage losses. Consequently, the applied durability test can distinguish between reversible and irreversible degradation effects and allows the evaluation of the impact of these effects on the cell performances at different specific current densities in a single test.

The single cell voltage values of all 19 cells recorded at $1.00,0.42$, and $0.05 \mathrm{~A} \mathrm{~cm}^{-2}$ during the durability test are provided in Figure 5 (A), (B) and (C), respectively. Degradation rates have been calculated (i) by linear regression of the voltage values recorded $1 \mathrm{~h}$ after each begin of test block and (ii) by linear regression of the voltage values monitored at the end of each test block. The first approach provides the degradation rate $A_{\text {after }}$ which corresponds to the irreversible degradation $A_{\text {irr, }}$ assuming that the refresh interruptions lead to a full recovery of reversible losses. The second approach gives the rate $A_{\text {before }}$ which is a combination of reversible and irreversible degradation. As an example, in the inset of Figure 6 (A), linear regressions used to determine $\mathrm{A}_{\text {after }}$ and $\mathrm{A}_{\text {before }}$ are indicated by a red dash-dotted line and a blue dashed line, respectively. 
The respective degradation rates $A_{\text {after }}=A_{\text {irr }}$ and $A_{\text {before }}=A_{\text {irr }}+A_{\text {rev }}$ evaluated at $1 \mathrm{~A} \mathrm{~cm}^{-2}$ for each cell of the rainbow stack are provided in Figure 6 (A) as red and blue bars, respectively. Apparently, for Cells 4, 5, and 7 as well for cell 11, 12 and 14 (i.e. cells using cathodic Pt loadings $<0.4 \mathrm{mg} \mathrm{cm}^{-2}$, see Table 1 ), the difference between $\mathrm{A}_{\text {before }}$ and $\mathrm{A}_{\text {after }}$ is significant while for the other cells $A_{\text {after }}$ largely corresponds to $A_{\text {before. }}$ This difference $A_{\text {before }}-A_{\text {after }}=$ $A_{\text {irr }}+A_{\text {rev }}-A_{\text {irr }}=A_{\text {rev }}$ represents the increasing impact of several reversible effects on the performance decay of each cell during operation in each test block. For a better understanding, $\mathrm{A}_{\text {rev }}$ determined at $0.05,0.42$ and $1.00 \mathrm{~A} \mathrm{~cm}^{-2}$ is plotted in Figure 6 (B) versus the cathodic ECSA, which is proportional to the nominal Pt loading (it is noted that for the following degradation analysis only cells containing EWii MEAs have been considered). Evidently, for cells with a cathodic ECSA in the range of 200-250 $\mathrm{cm}_{\mathrm{Pt}}{ }^{2} \mathrm{~cm}_{\text {electrode }}{ }^{-2}$, which corresponds to nominal cathode loading of $0.4 \mathrm{mg} \mathrm{cm}^{-2}, \mathrm{~A}_{\text {rev }}$ is close to zero. Consequently, the reversible degradation does not change from one test block to another and can therefore be considered as constant. In contrast, $\mathrm{A}_{\mathrm{rev}}$ is clearly positive for cells with $\mathrm{ECSA} \leq 150 \mathrm{~cm}_{\mathrm{Pt}}{ }^{2} \mathrm{~cm}_{\text {electrode }}{ }^{-2}$, i.e. for cells with cathodic loadings $<0.4 \mathrm{mg} \mathrm{cm}^{-2}$. The positive values indicate that the impact of the reversible degradation effects increases from one test block to another: the reversible degradation is accelerated for the affected cells. It can be concluded that cathode Pt loadings between 0.3 and $0.4 \mathrm{mg} \mathrm{cm}^{-2}$ represent an upper threshold value below which reversible degradation effects have a major impact on the performance decay independent on the current density at which the cells are operated. A similar behavior has been observed in our recent paper where reversible and irreversible degradation of MEAs with cathodic loadings of 0.4 and $0.2 \mathrm{mg} \mathrm{cm}^{-2}$ has been studied [23].

In order to investigate the influence of Pt loading on the irreversible degradation, the rates $\mathrm{A}_{\mathrm{after}}=\mathrm{A}_{\text {irr }}$ have been determined for the individual EWii Fuel Cells MEAs at 0.05, 0.42 and $1.00 \mathrm{~A} \mathrm{~cm}^{-2}$. In Figure 7, the rate $\mathrm{A}_{\text {irr }}$ is plotted as a function of current density and cathodic Pt loading (in our study anodic Pt loading was found to have no measurable influence on 
degradation rate). At low current densities, the irreversible degradation rate is almost constant for the different cathodic Pt loadings. At higher current densities, the MEAs with cathodic Pt loadings $\leq 0.2 \mathrm{mg} \mathrm{cm}^{-2}$ show significantly increased degradation rates up to $300 \%$, compared to the corresponding degradation rates at low current density. In contrast, for MEAs with 0.3 and $0.4 \mathrm{mg} \mathrm{cm}^{-2}$ cathodic Pt loadings the degradation rates at high current densities are only slightly higher by roughly 50\%, than at low current densities. Consequently, a threshold cathodic Pt loading of around $0.2-0.3 \mathrm{mg} \mathrm{cm}^{-2}$ is detected for the studied electrodes. Further lowering of the Pt loading on the cathode leads to an increased irreversible degradation. According to Arisetty et al. [20], this different behavior of degradation at low cathode loadings (MEAs with 0.15 and $0.4 \mathrm{mg}_{\mathrm{Pt}} \mathrm{cm}^{-2}$ were tested by ASTs) can be attributed to a faster increasing mass transport resistance at low Pt loadings and not to changes in the ECSA [20]. Nevertheless, we investigated the impact of ECSA losses on the irreversible degradation behavior in our study. In contrast to [20], we found a correlation between the relative ECSA loss, cathodic Pt loading and irreversible degradation rate. The reason for the increased irreversible degradation at low Pt loadings is likely due to Pt particle growth and dissolution [18] suggested by the ECSA loss observed in Figure 8 (A) as well as by carbon corrosion indicated by Figure 8 (B). Even though general conclusions can be drawn from Figure 8 (A), the data cannot be evaluated quantitatively due to strong scattering of the ECSA values. In accordance with the not recognizable impact of the anodic Pt loading on the cell performance and the fact that the anodic ECSA loss is substantially lower than the cathodic ECSA loss, it is not considered as main contribution to the observed irreversible degradation. In the case of the cathode, a trend that the relative ECSA loss increases with decreasing cathodic Pt loading is apparent and suggests a relation with the data in Figure 7. Specifically, while at 0.4-0.3 $\mathrm{mg}_{\mathrm{Pt}} \mathrm{cm}^{-2}$ a slight ECSA loss of roughly $10-20 \%$ is determined after the durability test, for $0.2-0.15 \mathrm{mg}_{\mathrm{Pt}} \mathrm{cm}^{-2}$ an ECSA loss in the range of $30 \%$ occurs. The up to $300 \%$ higher irreversible degradation observed for low Pt loadings and high current densities is principally 
consistent with the higher relative ECSA loss at low Pt loadings since in this case an ECSA loss is particularly severe due to the intrinsically higher Pt utilization that is required to maintain the performance at high current densities. As mentioned above another contribution to ECSA loss is carbon corrosion which is evidenced by the relative reduction of double layer capacitances $Q_{D L}$ shown in Figure 8 (B). $Q_{D L}$ is proportional to the differences of the currents during upscan and downscan in the CVs measured in the double layer region which were evaluated at $400 \mathrm{mV}$ vs. DHE. The relative reduction of $\mathrm{Q}_{\mathrm{DL}}$ shows the same trend as the relative ECSA loss. The carbon corrosion is likely caused by water flooding of the thin electrodes (low Pt loadings).

\section{Conclusions}

In this paper a 19 cells PEMFC rainbow stack study on the impact of the Pt loading of Pt/C catalysts on the performance and degradation is presented. The Pt loadings of the MEAs that are used in the stack were varied in the range of $0.05-0.20 \mathrm{mg}_{\mathrm{Pt}} \mathrm{cm}^{-2}$ on the anode and $0.15-$ $0.40 \mathrm{mg}_{\mathrm{Pt}} \mathrm{cm}^{-2}$ on the cathode by variation of the thicknesses of the catalyst layers with fixed $\mathrm{Pt} / \mathrm{C}$ composition. The test was conducted under dynamic automotive conditions using the FC-DLC test protocol, developed in the European Stack-Test project which allows discrimination between reversible and irreversible degradation at different current densities in a single experiment. From the performance data (investigated in the range of 0-1.4 $\mathrm{A} \mathrm{cm}^{-2}$ ) and degradation data (investigated in the range of 0-1.0 $\mathrm{A} \mathrm{cm}^{-2}$ ) following conclusions are drawn for the studied electrodes:

- The cell performance is independent of the anodic Pt loading for current densities up to $1.4 \mathrm{~A} \mathrm{~cm}^{-2}$.

- A non-linear dependence of the performance on the cathodic Pt loading was found. The performance drops significantly for Pt-loadings $<0.2-0.25 \mathrm{mg}_{\mathrm{Pt}} \mathrm{cm}^{-2}$ and for current densities $\geq 1.0 \mathrm{~A} \mathrm{~cm}^{-2}$. 
- Reversible degradation is constant for subsequent test blocks if the cathodic Pt loading is $0.4 \mathrm{mg}_{\mathrm{Pt}} \mathrm{cm}^{-2}$; for cathodic loadings $<0.4 \mathrm{mg}_{\mathrm{Pt}} \mathrm{cm}^{-2}$ the reversible degradation increases from one test block to another (accelerated reversible degradation).

- Irreversible degradation depends on the cathodic Pt loading. $0.2-0.3 \mathrm{mg} \mathrm{cm}^{-2}$ is found to be a threshold value below which the irreversible degradation is particularly high for current densities $>0.4 \mathrm{~A} \mathrm{~cm}^{-2}$.

\section{Acknowledgements}

The research leading to these results has received funding from the European Union's Seventh Framework Programme (FP7/2007-2013) for Fuel Cell and Hydrogen Joint Technology Initiative under Grant No. 303452 (Impact). The authors thank Siegfried Graf and Stefan Anderle for setting up the fuel cell stack test station. The authors also thank Madeleine Odgaard from EWii Fuel Cells for providing the required CCMs for the rainbow stack.

\section{References}

“COMMUNICATION FROM THE COMMISSION TO THE EUROPEAN PARLIAMENT, THE COUNCIL, THE EUROPEAN ECONOMIC AND SOCIAL COMMITTEE AND THE COMMITTEE OF THE REGIONS, On the review of the list of critical raw materials for the EU and the implementation of the Raw Materials Initiative”, European Commission. 2014. “IPA Fact Sheet, AUTOCATALYSTS AND PLATINUM GROUP METALS (PGMs).” http://ipaews.com/assets/sustainability/Autocatalyst\%20Fact\%20Sheet_LR.pdf?PHPSESSI $\mathrm{D}=8 f 924 \mathrm{aa0e30f81ba7fe97c7449665b58}$

[3] Eurostat, "http://ec.europa.eu/eurostat/statisticsexplained/index.php/Passenger_cars_in_the_EU.” 
[4] European Automobile Manufacturers Association, http://www.acea.be/statistics/tag/category/cubic-capacity-average-power

[5] IMPACT: Improved lifetime of automotive application fuel cells with ultra-low Pt-loading, FCH JU Grant No. 303452.

[6] A. Kongkanand and M. F. Mathias, J. Phys. Chem. Lett. 2016, 7, 1127.

[7] H. A. Gasteiger, J. E. Panels, and S. G. Yan, J. Power Sources 2004, 127, 162.

[8] E. Billy, F. Maillard, L. Guetaz, F. Emieux, C. Thurier, P. Doppelt, S. Donet, and S. Mailley, J. Power Sources 2010, 125, 2732.

[9] PEM Fuel Cell Electrocatalysts and Catalyst Layers; Jiujun Zhang (Editor); Springer-Verlag Limited London, 2008; p. 611

[10] Z. Qi and A. Kaufman, J. Power Sources 2003, 113, 37.

[11] A. Kongkanand and M. F. Mathias, J. Phys. Chem. Lett. 2016, 7, 1127.

[12] R. K. Ahluwalia, J.-K. Peng, X.Wang, D. A. Cullen, and A. J. Steinbach, J. Electrochem. Soc. 2017, 164, F306.

[13] T. Xie, W. Jung, T. Kim, P. Ganesan, and B. N. Popov, J. Electrochem. Soc. 2014, 161, F1489.

[14] A. Kriston, T. Xie, and B. N. Popov, Electrochim. Acta 2014, 121, 116.

[15] S. H. Ahn, S. Jeon, H.-Y. Park, S.-K. Kim, H.-J. Kim, E. Cho, D. Henkensmeier, S. J. Yoo, S. W. Nam, T.-H. Lim, and J. H. Jang, Int. J. Hydrogen Energy 2013, $38,9826$.

[16] X. Yu and S. Ye, J. Power Sources 2007, 172, 145.

[17] S. Zhang, X. Yuan, J. Ng, C. Hin, H. Wang, K. A. Friedrich, and M. Schulze, J. Power Sources 2009, 194, 588.

[18] C. G. Chung, L. Kim, Y. W. Sung, J. Lee, and J. S. Chung, Int. J. Hydrogen Energy 2009, 348974. 
[19] Z. Yang, S. Ball, D. Condit, and M. Gummalla, J. Electrochem. Soc. 2011, 158, B1439.

[20] S. Arisetty, X. Wang, R. K. Ahluwalia, R. Mukundan, R. Borup, J. Davey, D. Langlois, F. Gambini, O. Polevaya, and S. Blanchet, J. Electrochem. Soc. 2012, 159, B455.

[21] Georgios Tsotridis, Alberto Pilenga, Giancarlo De Marco, Thomas Malkow; EU HARMONISED TEST PROTOCOLS FOR PEMFC MEA TESTING IN SINGLE CELL CONFIGURATION FOR AUTOMOTIVE APPLICATIONS; JRC Science for Policy report, 2015; EUR 27632 EN; doi 10.2790/54653

[22] Stack-Test Test Module D-02 “Load Cycling Durability” http://stacktest.zswbw.de/media-centre.html. 2016.

[23] P. Gazdzicki, J. Mitzel, D. G. Sanchez, M. Schulze, and K. A. Friedrich, J. Power Sources 2016, 327, 86.

[24] J. Mitzel, E. Gülzow, A. Kabza, J. Hunger, S. S. Araya, P. Piela, I. Alecha, G. Tsotridis, Int. J. Hydrogen Energy 2016, 41, 21415.

[25] T. Ruiu, A. M. Dreizler, J. Mitzel, and E. Gülzow, J. Power Sources 2016, 303 257.

[26] L. Dubau, L. Castanheira, M. Chatenet, F. Maillard, J. Dillet, G. Maranzana, S. Abbou, O. Lottin, G. De Moor, A. El Kaddouri, C. Bas, L. Flandin, E. Rossinot, N. Caque, Int. J. Hydrogen Energy 2014, 39, 21902

[27] Stack-Test Project (FCH JU Grant No. 303445), Test modules available at http://stacktest.zsw-bw.de/media-centre/test-modules.

[28] K. Kinoshita, P. Stonehart, Preparation and characterization of highly dispersed electrocatalytic materials, in: J. o’m. Bockris and B. E. Conway (Ed.), Modern Aspects of Electrochemistry, Plenum Press, New York, 1977, pp. 183-266. 
Tables

Table 1: Pt-loadings of the individual cells of the rainbow stack.

\begin{tabular}{|c|c|c|c|}
\hline Cell No. & Name & $\begin{array}{l}\text { Anode Loading / } \\
\text { mg }_{\mathbf{P t}} \mathbf{c m}^{-2}\end{array}$ & $\begin{array}{l}\text { Cathode Loading / } \\
\mathbf{m g}_{\mathrm{Pt}} \mathbf{c m}^{-2}\end{array}$ \\
\hline 1 & Reference & 0.20 & 0.40 \\
\hline 2 & Reference & 0.20 & 0.40 \\
\hline 3 & Reference & 0.20 & 0.40 \\
\hline 4 & MEA1 & 0.05 & 0.20 \\
\hline 5 & MEA2 & 0.05 & 0.30 \\
\hline 6 & MEA3 & 0.05 & 0.40 \\
\hline 7 & MEA4 & 0.05 & 0.15 \\
\hline 8 & MEA5 & 0.10 & 0.40 \\
\hline 9 & MEA6 & 0.20 & 0.40 \\
\hline 10 & Reference & 0.20 & 0.40 \\
\hline 11 & MEA1 & 0.05 & 0.20 \\
\hline 12 & MEA2 & 0.05 & 0.30 \\
\hline 13 & MEA3 & 0.05 & 0.40 \\
\hline 14 & MEA4 & 0.05 & 0.15 \\
\hline 15 & MEA5 & 0.10 & 0.40 \\
\hline 16 & MEA6 & 0.20 & 0.40 \\
\hline 17 & Reference & 0.20 & 0.40 \\
\hline 18 & Reference & 0.20 & 0.40 \\
\hline 19 & Reference & 0.20 & 0.40 \\
\hline
\end{tabular}


Table 2: Protocol of the Rainbow Stack durability test.

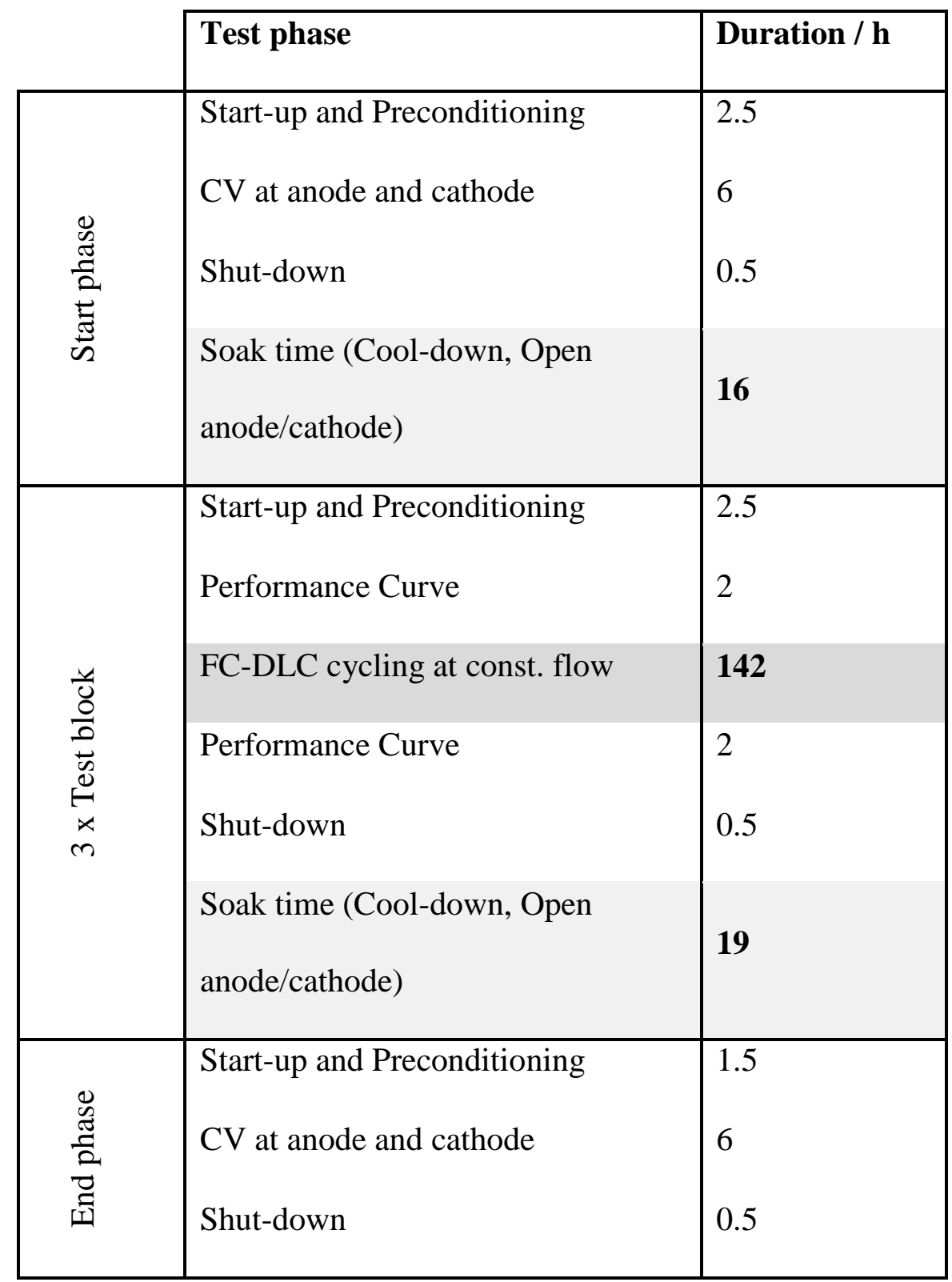


Figure Captions
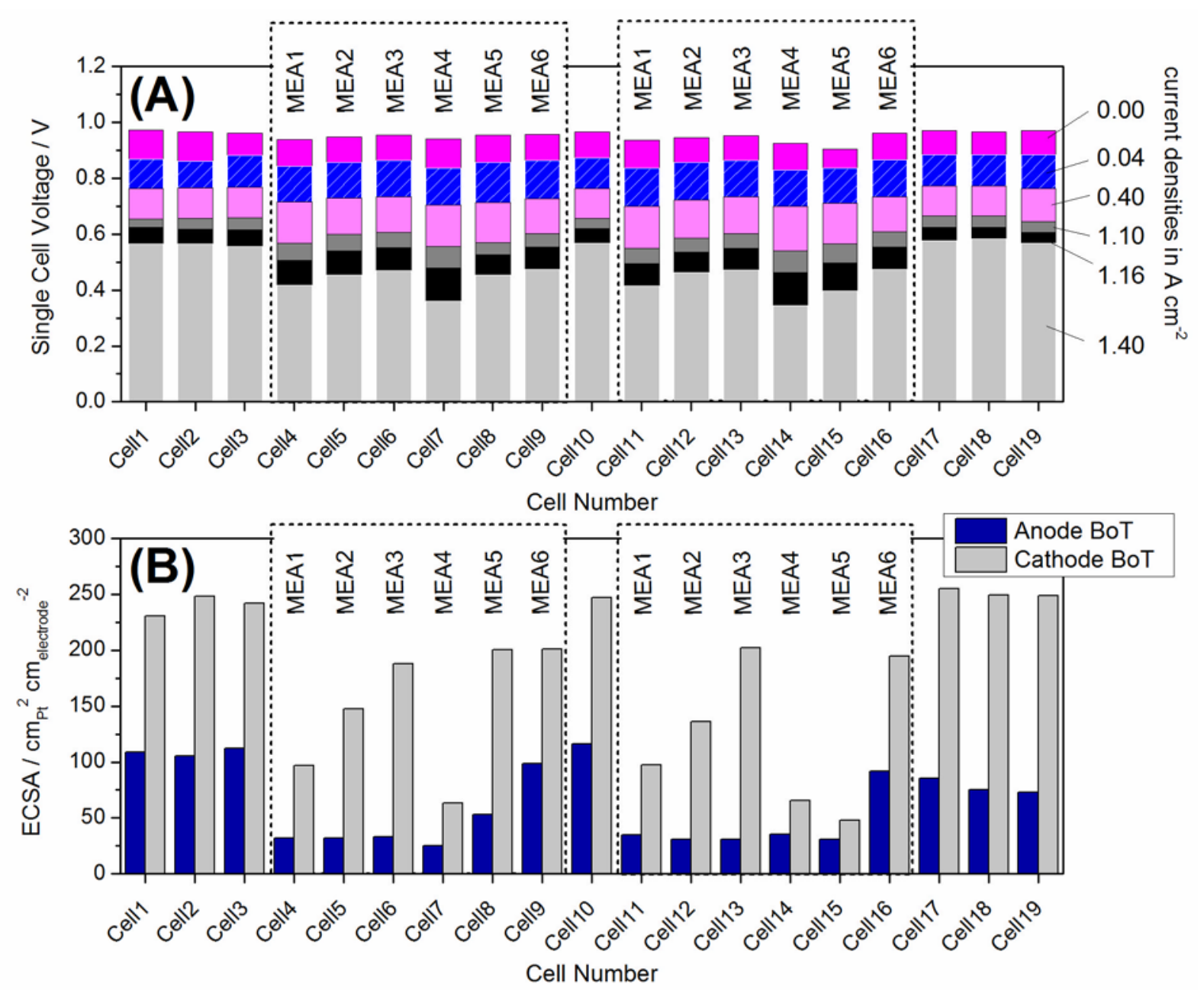

Figure 1: Characterization of the individual cells of the Rainbow Stack. (A) Performance characteristics: voltage levels recorded at the indicated current densities. (B) Anode and cathode ECSA measured at BoT. 

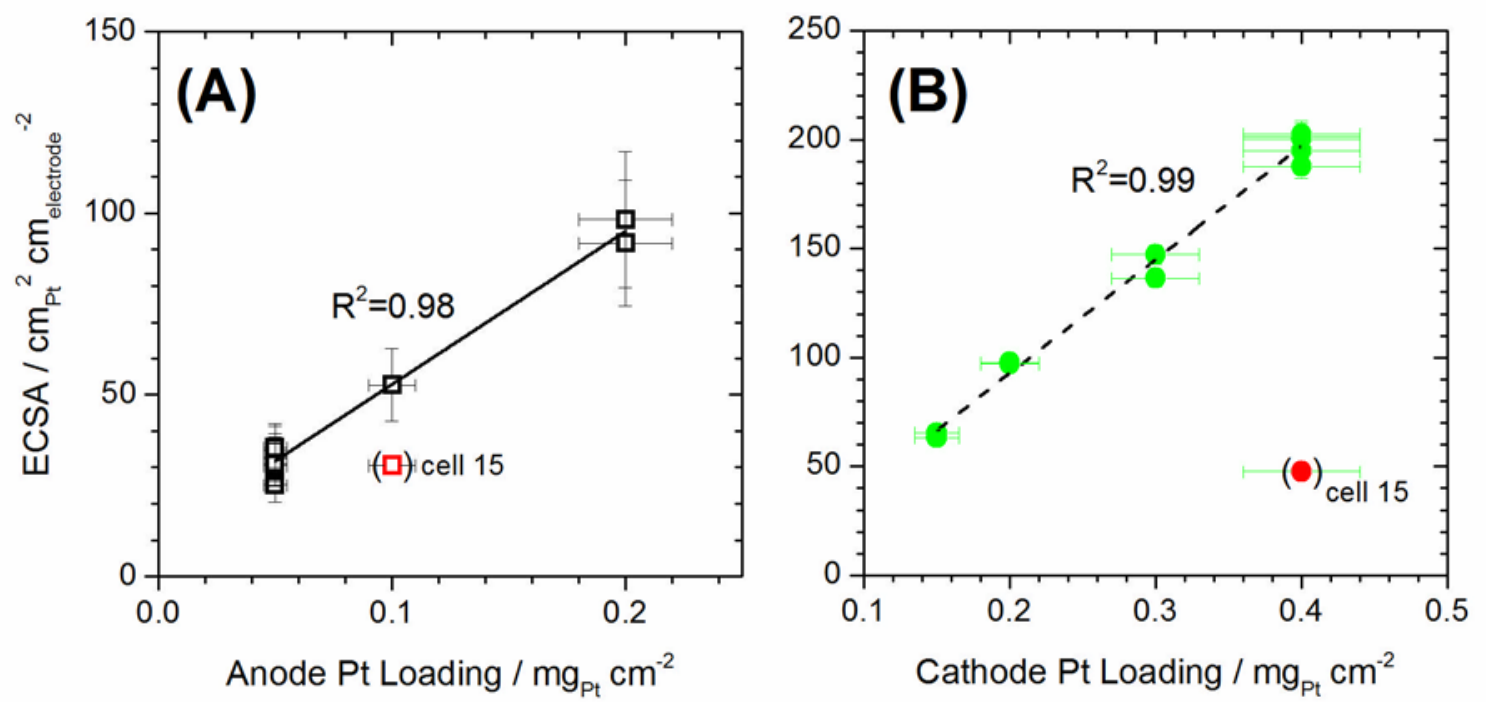

Figure 2: Correlation of ECSA and Pt loading for anodes and cathodes of EWii MEAs.
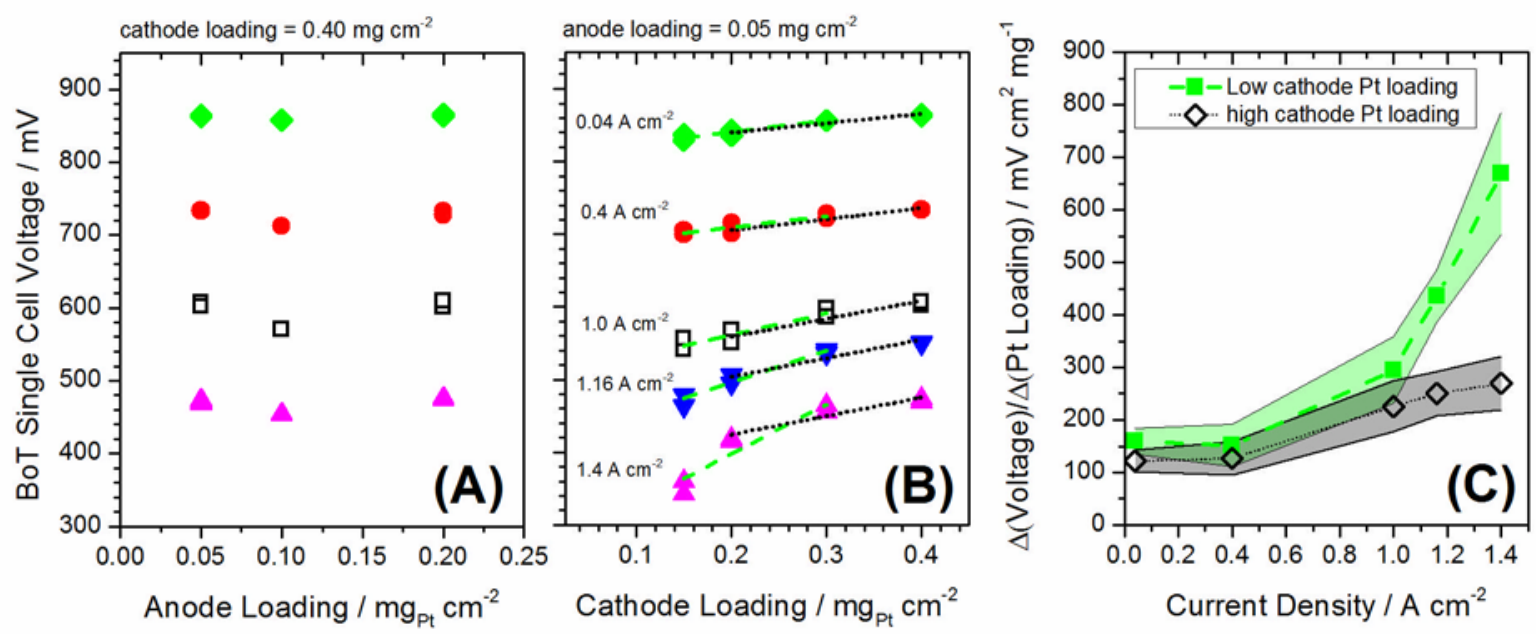

Figure 3: (A) Single cell BoT voltages versus anode Pt loading (cathode Pt loading constant at $0.40 \mathrm{mg} \mathrm{cm}^{-2}$ ) (B). Single cell BoT voltages versus cathode Pt loading (anode Pt loading constant at $0.05 \mathrm{mg} \mathrm{cm}^{-2}$ ). The different data points correspond to different current densities as indicated in the figure. The dashed and dotted lines are linear regressions of data in the cathodic Pt loading ranges $0.20-0.40 \mathrm{mg} \mathrm{cm}^{-2}$ (high Pt loadings) and $0.05-0.30 \mathrm{mg} \mathrm{cm}{ }^{-2}$ (low Pt loadings), respectively. (C) Slopes of the dashed and dotted curves from panel (B) plotted versus current density. 

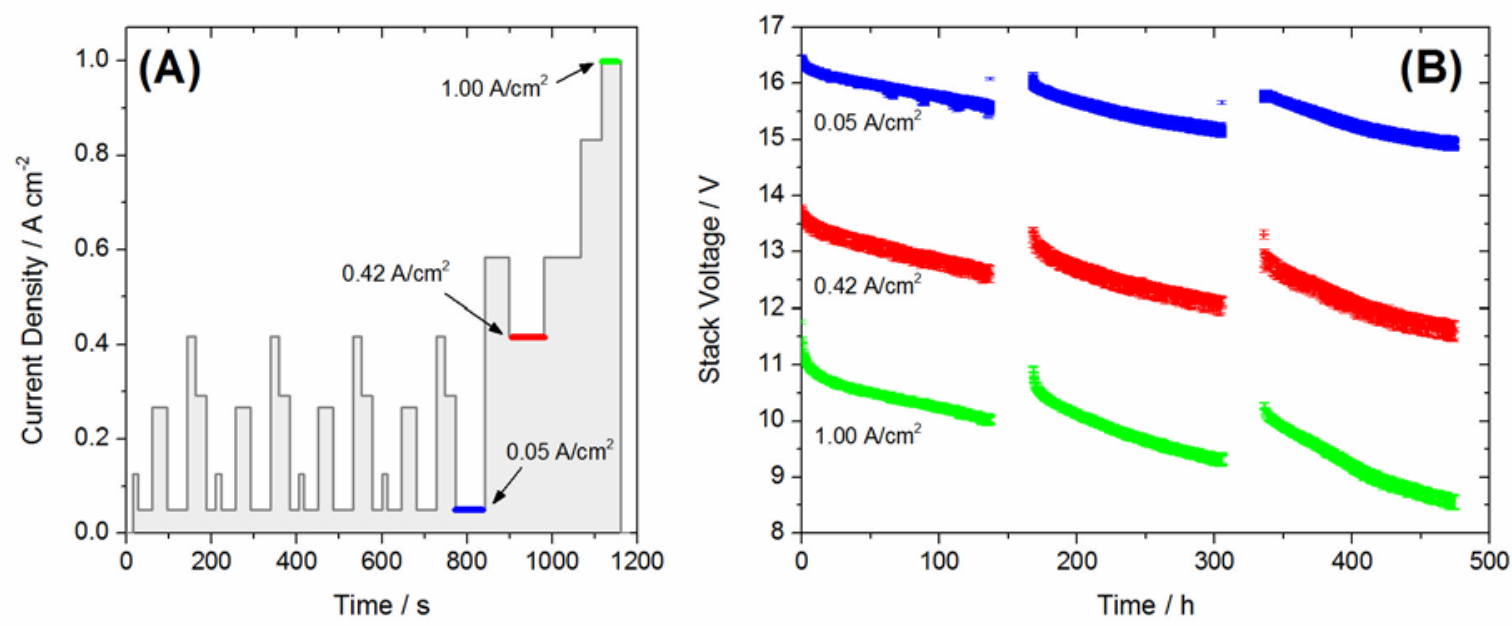

Figure 4: (A) A single cycle of the FC-DLC protocol along with the three current densities at which the stack voltages have been evaluated. (B) Stack voltages, recorded at the indicated current densities. The continuous operation has been interrupted in order to recover reversible voltage losses to discriminate between reversible and irreversible degradation. 

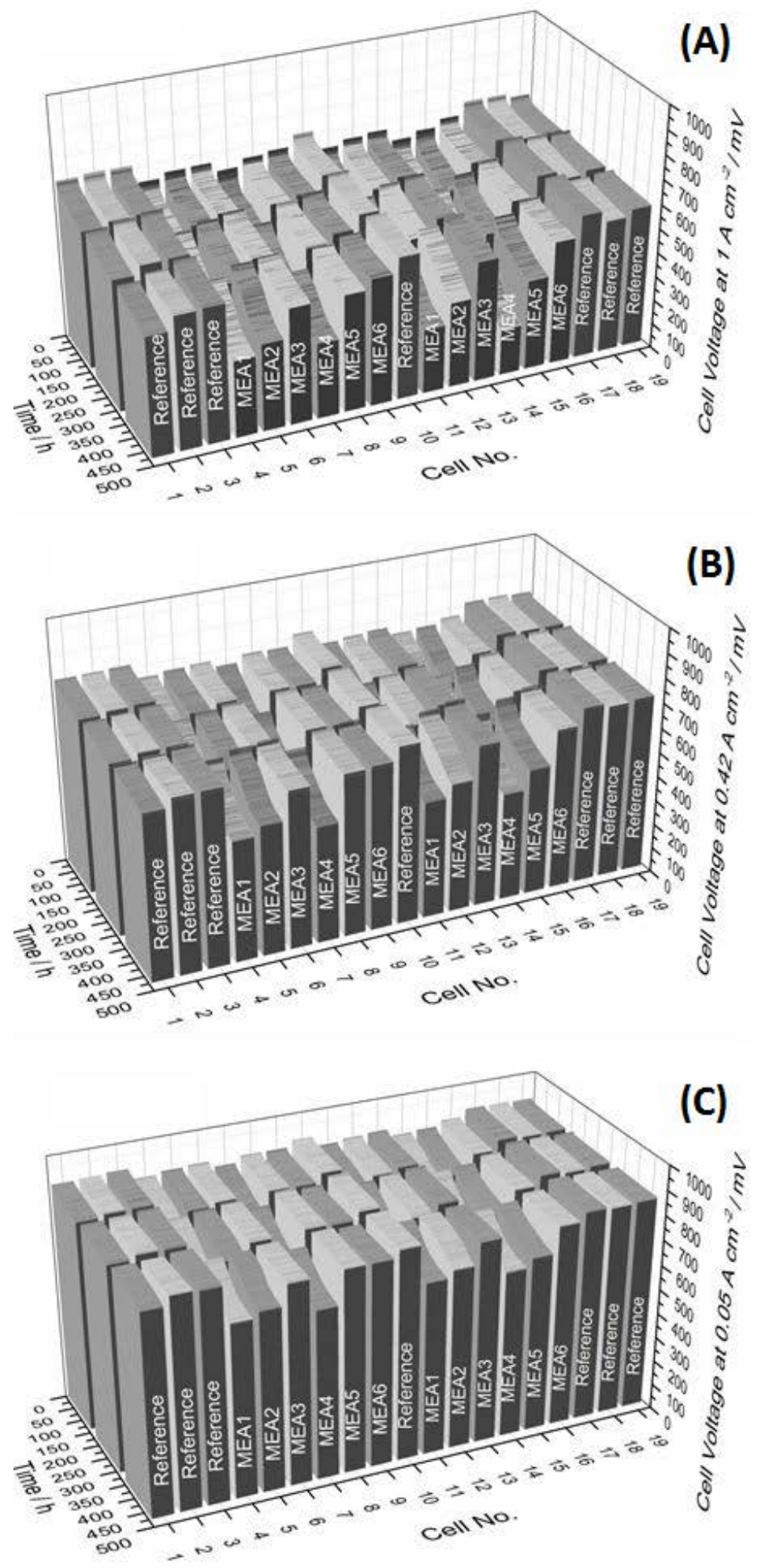

Figure 5: Durability test performed by using a DLR rainbow stack. (A), (B) and (C) show single cell voltages versus operation time, recorded at 1.00, 0.42 and $0.05 \mathrm{~A} \mathrm{~cm}^{-2}$, respectively. 

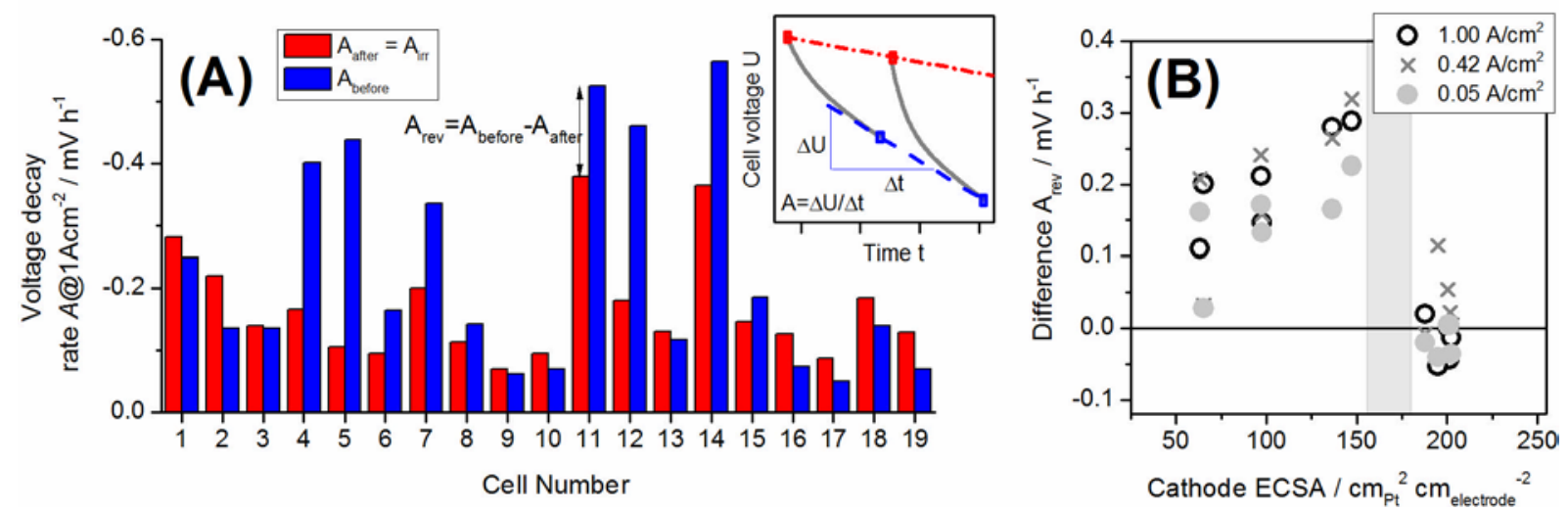

Figure 6: (A) Voltage decay rates $A$ versus cell number, calculated at $1 \mathrm{~A} \mathrm{~cm}^{-2}$ current density by using voltage values before (blue bars, $A_{\text {before}}$ ) and after refresh (red bars, $A_{\text {after }}$ ) as indicated in the inset through dashed and dash-dotted lines. (B) Differences of the decay rates $A_{\text {rev }}=A_{\text {before }}-A_{\text {after }}$, evaluated at $1.0,0.42$ and $0.05 \mathrm{~A} \mathrm{~cm}^{-2}$, are plotted versus the cathodic ECSA (EWii MEAs only).

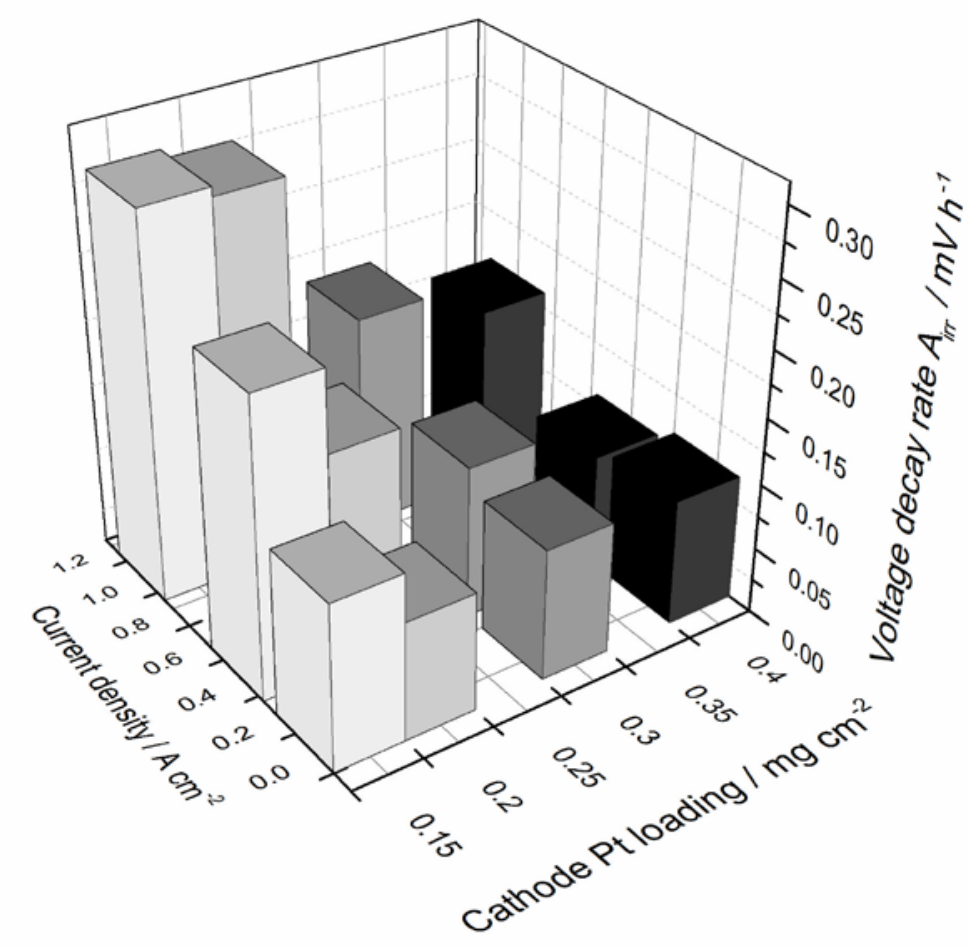

Figure 7: Irreversible voltage decay rate $A_{\text {irr }}$ as a function of current density and cathode Pt loading. Only cells with a constant anode Pt loading of $0.05 \mathrm{mg} \mathrm{cm}^{-2}$ have been evaluated, i.e. cells No. 4-7 and 11-14. 

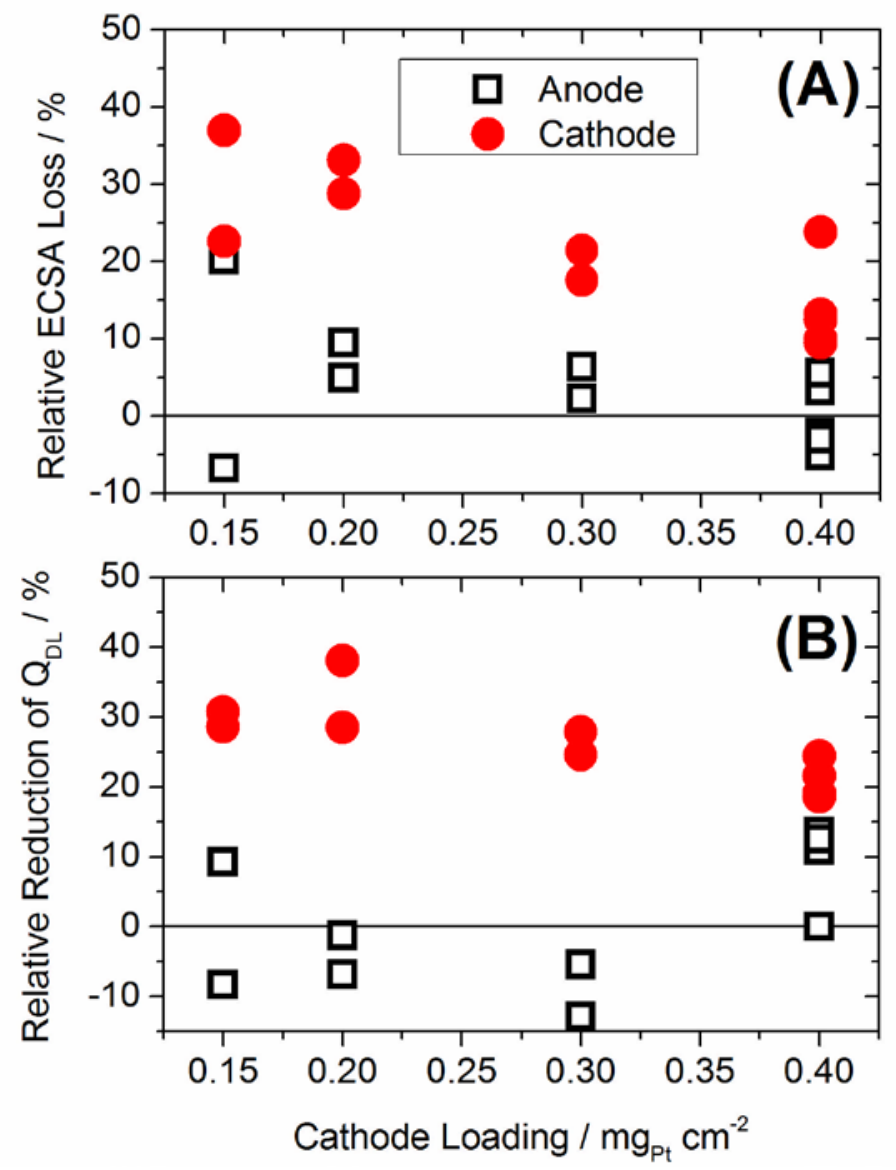

Figure 8: (A) Relative ECSA loss at the cathode and anode versus cathode Pt loading, determined from CV measurements at BoT and EoT. (B) Relative reduction of the double layer capacitance $\mathrm{Q}_{\mathrm{DL}}$ at the cathode and anode versus cathode Pt loading, determined at 400 $\mathrm{mV}$ from CV measurements at BoT and EoT. 